\title{
Renal Biopsy in Very Elderly Patients: Data from the Spanish Registry of Glomerulonephritis
}

\author{
Eduardo Verde $^{\mathrm{a}}$ Borja Quiroga ${ }^{\mathrm{a}}$ Francisco Riverab $^{\mathrm{b}} \quad$ Juan M. López-Gómez ${ }^{\mathrm{a}}$ \\ on behalf of all the members of the Spanish Registry of Glomerulonephritis

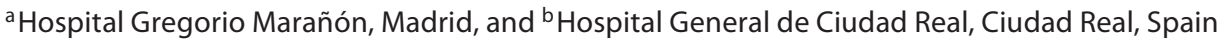

\section{Key Words}

Elderly - Renal biopsy - Glomerulonephritis - Amyloidosis •

Nephrotic syndrome $\cdot$ Acute renal failure $\cdot$ Vasculitis

\begin{abstract}
Background: Studies on renal histology results in very elderly patients are extremely rare. Methods: We analyzed histology and clinical findings in patients aged over 85 years undergoing renal biopsy and whose data were included in the Spanish Registry of Glomerulonephritis between 1994 and 2009. Results: A total of 17,680 native kidney biopsies were taken: 71 (0.4\%) were from patients aged over 85 years. Acute kidney injury (AKI) was the main indication for biopsy (47\%), followed by nephrotic syndrome (32\%). Amyloidosis was the most common histological diagnosis (16.9\%), followed by crescentic glomerulonephritis type 3 associated with systemic vasculitis (14.1\%). When histological findings were correlated with clinical syndromes, we found that amyloidosis was the leading cause of AKI (18.8\%), and also the main determinant of nephrotic syndrome, with the same frequency as membranous nephropathy (22\%). Crescentic glomerulonephritis type 3 associated with vasculitis was related to a greater diversity of clinical syndromes, especially chronic kidney disease (40\%) and AKI (40\%). Conclusions:
\end{abstract}

Renal biopsy in the very elderly provides us with useful information, despite the advanced age of the patients. AKI and nephrotic syndrome are the main indication for renal biopsy in this subgroup of patients, and amyloidosis is the most frequent histological pattern associated with both syndromes.

Copyright $\odot 2012$ S. Karger AG, Basel

\section{Introduction}

Renal biopsy continues to occupy a prominent place in the diagnosis of renal disease. The Spanish Registry of Glomerulonephritis has been collecting data on renal biopsies since 1994, and the information it provides can help to improve our knowledge of these diseases [1-3].

In recent years, several studies have analyzed renal disease in elderly patients [4-8]. However, the concept of old age has been changing in developed countries. The first publications in this field considered elderly patients to be those aged over 60 years $[4,5]$. This age limit has gradually increased, leading to a broad spectrum of cut-offs that make it difficult to compare data between series. The scientific literature continues to publish studies which establish 65 years, or even 60 years as

\section{KARGER}

Fax +4161306 1234 E-Mail karger@karger.ch www.karger.com

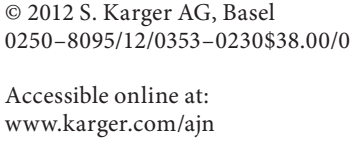

Juan M. López-Gómez

Service of Nephrology, Hospital Gregorio Marañón

Dr. Esquerdo, 46

ES-28007 Madrid (Spain)

E-Mail juanmlopez@senefro.org 
a cut-off $[9,10]$. Therefore, a higher universal cut-off has been sought to define the elderly population, although few data have been published to establish a definition. To date, only two studies, both conducted in the USA, have analyzed renal histology findings in patients aged over 80 years $[11,12]$. The present study examines a subgroup of even older patients, namely those aged 85 years and over.

Increased life expectancy, together with scientific and medical progress, means that elderly patients often have chronic diseases and are more susceptible to acute events, which may last longer and be more severe than in other age groups. Consequently, the number of therapeutic interventions has also increased in this age group. Renal disease is one of the best examples. A recent review analyzes current problems in the field of geriatric nephrology [13].

Renal biopsy provides important diagnostic information in elderly patients. According to some studies, this technique has enabled specific therapeutic interventions to be applied in more than $40 \%$ of cases [11], and ultrasound-guided biopsy has minimized the risk of complications. Therefore, age should not be considered a contraindication and the risk-benefit ratio should be assessed on an individual basis $[14,15]$.

We analyzed native kidney biopsies performed from 1994 to 2009 and recorded in the Spanish Registry of Glomerulonephritis in a very elderly population ( $>85$ years). No similar studies have examined this approach to date. As this subgroup is growing, we feel that it is necessary to determine the clinicopathological profile of these patients.

\section{Materials and Methods}

We analyzed all native renal biopsies taken from patients aged over 85 years and included in the Spanish Registry of Glomerulonephritis between 1994 and 2009, as well as the clinical indication. Each sample was analyzed by pathologists from the participating hospitals using specific techniques, mainly light microscopy and direct immunofluorescence (IgG, IgA, IgM, C3, C1q, fibrinogen, and light-chain antibodies). The study was completed by electron microscopy when considered necessary for diagnosis. A questionnaire on the patient's epidemiological and clinical data was completed.

We established the following definitions: (1) acute kidney injury (AKI): rapid deterioration of glomerular filtration rate (GFR), with or without oligoanuria or rapidly progressive renal failure, including worsening of chronic kidney disease; (2) nephrotic syndrome: proteinuria $\geq 3.5 \mathrm{~g} / \mathrm{day} / 1.73 \mathrm{~m}^{2}$ and serum albumin $<2.5 \mathrm{~g} / \mathrm{dl}$; (3) acute nephritic syndrome, oliguric AKI with edema, hematuria and hypertension; (4) asymptomatic uri- nary abnormalities: proteinuria $<3.5 \mathrm{~g} /$ day and/or hematuria with more than 3 red blood cells per field without clinical manifestations; (5) arterial hypertension: blood pressure $\geq 140 / 90 \mathrm{~mm}$ $\mathrm{Hg}$ or antihypertensive treatment irrespective of blood pressure, and (6) chronic kidney disease: persistent serum creatinine $\geq 1.5$ $\mathrm{mg} / \mathrm{dl}$.

The questionnaire was applied to obtain the following information: identification code, date of birth, gender, hospital, presence of hypertension and/or antihypertensive treatment, serum creatinine $(\mathrm{mg} / \mathrm{dl})$, creatinine clearance $(\mathrm{ml} / \mathrm{min})$, proteinuria (g/day), and urinary sediment. It also noted the main renal syndrome, the histological methods used with the sample, and the number of clusters obtained.

Primary glomerulonephritis (GN) were classified into nine groups: minimal change disease; focal segmental glomerulosclerosis (FSGS); endocapillary GN (defined by clinical features and specific immunological deposits in biopsy); crescentic GN (presence of crescents in $>50 \%$ of glomeruli) type 1 (accompanied by anti-glomerular basal membrane antibodies), type 2 (presence of immune complexes), and type 3 [necrotizing GN with or without anti-neutrophil cytoplasmic antibodies (ANCAs) or systemic vasculitis symptoms]; membranoproliferative GN type 1; dense deposit disease (also called membranoproliferative GN type 2); membranous nephropathy; IgA nephropathy, and non-IgA mesangioproliferative GN. Secondary GN were also classified into eight groups: fibrillar GN, lupus nephritis, connective tissue diseases (scleroderma and other diseases not included in other diagnosis), vasculitis (including crescentic GN type 3 or pauci-immune), Goodpasture syndrome, cryoglobulinemic GN, amyloidosis, and light-chain nephropathy. Tubulointerstitial nephritis was defined as acute or chronic. Finally, non-inflammatory renal diseases were classified as diabetic nephropathy, nephrosclerosis, acute tubular necrosis, myeloma kidney (or light-chain cast nephropathy) disease and thrombotic microangiopathy.

\section{Statistical Analysis}

The data were entered in a database (Microsoft Access ${ }^{\circledR}$ ). Statistical analysis was performed using SPSS for Windows Version $16.0^{\circledR}$ (SPSS, Chicago, Ill., USA). The normal distribution of the samples was determined using the Kolmogorov-Smirnov test. Values were expressed as medians (interquartile range) when the parameters did not follow a normal distribution. Qualitative variables were compared using the $\chi^{2}$ test and Fisher's exact test. A $p$ value $<0.05$ was considered significant.

\section{Results}

Between 1994 and 2009, a total of 17,680 native renal biopsies from 120 hospitals in Spain were included in the Spanish Registry of Glomerulonephritis. Of these, 71 ( $0.4 \%$ of the total) corresponded to patients aged over 85 years. Forty-three were men and 28 were women (male-to-female ratio of 1.5). Median age was 86 years (range 85-92). The general characteristics of the study population are shown in table 1 . Of note, serum creati- 


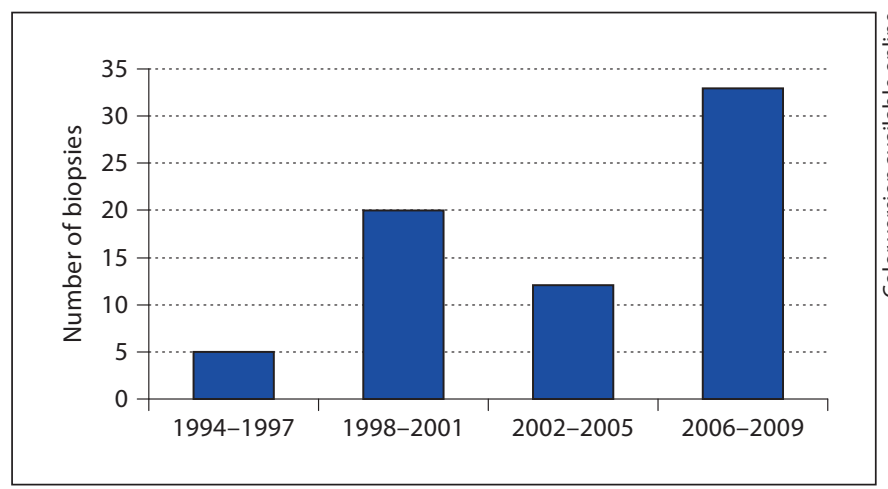

Fig. 1. Evolution of renal biopsies.

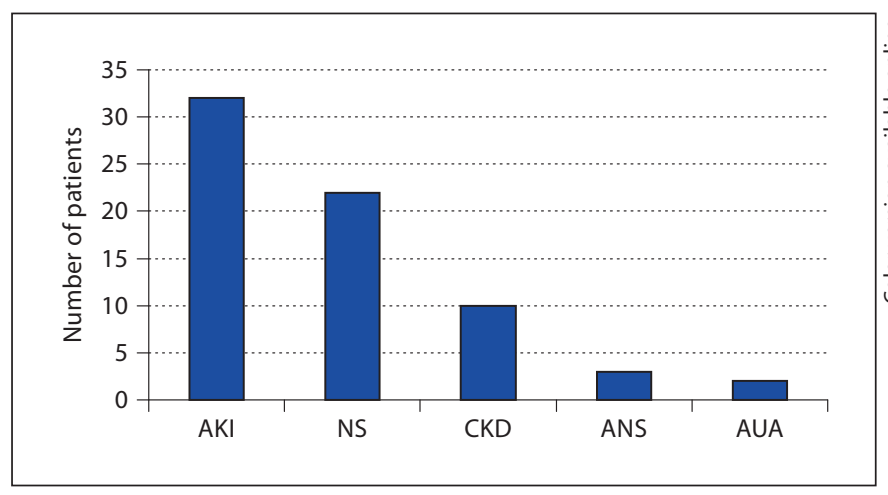

Fig. 2. $\mathrm{AKI}=$ Acute kidney injury; NS = nephrotic syndrome; ANS = acute nephritic syndrome; AUA = asymptomatic urinary abnormalities; CKD = chronic kidney disease.

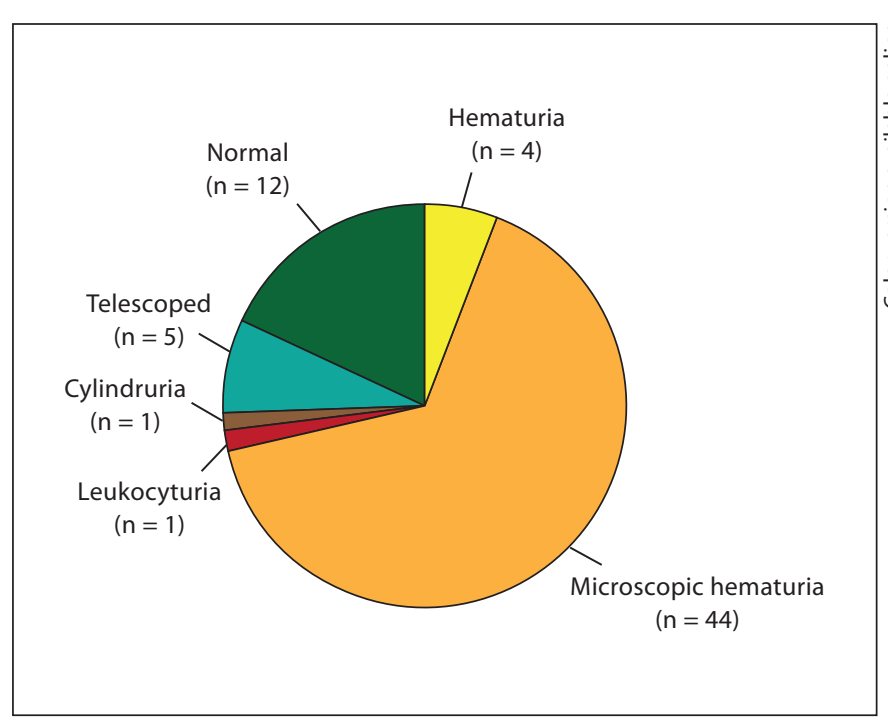

Fig. 3. Urinary sediment (data show the number of patients).
Table 1. Baseline characteristics of patients aged over 85 years

\begin{tabular}{|c|c|}
\hline Male/female & $43 / 28$ \\
\hline Age, years & $86.0^{1}$ \\
\hline Hypertension & $58 \%$ \\
\hline Serum creatinine, $\mathrm{mg} / \mathrm{dl}$ & $4.28^{1}$ \\
\hline Creatinine clearance, $\mathrm{ml} / \mathrm{min}$ & 12.5 \\
\hline Proteinuria, g/day & $3.7^{1}$ \\
\hline Glomeruli, $\mathrm{n}$ & $12^{1}$ \\
\hline
\end{tabular}

${ }^{1}$ Values are expressed as medians.

nine levels were high at the time of renal biopsy, with a median creatinine clearance for this population of 12.5 $\mathrm{ml} / \mathrm{min}$. Equally striking is the high proteinuria value, which was in the nephrotic range for more than half of the sample.

The number of renal biopsies in elderly patients increased toward the end of the study period: 33 of the 71 biopsies (48\%) were taken in the last 4 years (fig. 1). The indications for renal biopsy according to the different clinical syndromes are shown in figure 2. AKI (32 patients, $47 \%$ ) was the main indication for biopsy, followed by nephrotic syndrome $(22,32 \%)$ and chronic kidney disease $(9,13 \%)$. Regarding changes in urinary sediment, microscopic hematuria was the main finding in almost three-quarters of patients (71\%), but was never the indication for renal biopsy (fig. 3). Urinary sediment was unaltered at the time of renal biopsy in $18.3 \%$ of patients.

Histology results are shown in table 2. Amyloidosis (primary or related to a deposition of protein derived from immunoglobulin light-chain fragments, and AA, secondary or related to a chronic disease with fragments of acute phase reactants serum amyloid A deposition) was the most frequent diagnosis (16.9\%). Crescentic GN type 3 (vasculitis), which was associated with systemic vasculitis, was the second most frequent entity (14.1\%). Membranous nephropathy was the most frequent primary GN, representing almost $10 \%$ of histological diagnoses.

When clinical syndromes were correlated with histological findings, we found that amyloidosis and membranous nephropathy (22.7\% of cases each) were the most common entities in patients with nephrotic syndrome. Mesangial IgA nephropathy, FSGS, and minimal change disease had the same frequency among patients with nephrotic syndrome (9.1\%). Thirty-two patients (45\%) had AKI at the time of biopsy, being amyloidosis the most 
Table 2. Histological diagnosis

\begin{tabular}{|c|c|c|}
\hline Histological diagnosis & Cases & $\%$ \\
\hline Primary GN & 27 & 38 \\
\hline Membranous nephropathy & 7 & 9.9 \\
\hline Crescentic GN types 1 and 2 & 6 & 8.5 \\
\hline IgA nephropathy & 6 & 8.5 \\
\hline Endocapillary GN & 3 & 4.2 \\
\hline Minimal change disease & 2 & 2.8 \\
\hline Focal segmental glomerulosclerosis & 2 & 2.8 \\
\hline Membranoproliferative GN & 1 & 1.4 \\
\hline Secondary GN & 26 & 36.6 \\
\hline Amyloidosis & 12 & 16.9 \\
\hline Crescentic GN type 3 (vasculitis) & 10 & 14.1 \\
\hline Light-chain nephropathy & 2 & 2.8 \\
\hline Fibrillary GN & 1 & 1.4 \\
\hline Goodpasture syndrome & 1 & 1.4 \\
\hline Interstitial nephritis & 6 & 8.4 \\
\hline Acute interstitial nephritis & 3 & 4.2 \\
\hline Chronic interstitial nephritis & 3 & 4.2 \\
\hline Non-inflammatory renal disease & 12 & 16.8 \\
\hline Diabetic glomerulopathy & 2 & 2.8 \\
\hline Sclerosis ${ }^{1}$ & 2 & 2.8 \\
\hline Acute tubular necrosis & 1 & 1.4 \\
\hline Myeloma kidney $^{2}$ & 1 & 1.4 \\
\hline Unclassifiable & 3 & 4.2 \\
\hline Other ${ }^{3}$ & 3 & 4.2 \\
\hline
\end{tabular}

\footnotetext{
${ }^{1}$ Presence of scarring without the typical presentation of the primary FSGS.

${ }^{2}$ Myeloma kidney or light chain cast nephropathy.

${ }^{3}$ Other refers to mixed histopathological findings.
}

common cause (18.8\%), followed by crescentic GN types 1 and 2 with $15.6 \%$ and type 3 with $12.5 \%$ (table 3 ).

Crescentic GN type 3 (vasculitis) was the leading cause of chronic kidney disease as an indication for biopsy (44\%). In addition, this entity was associated with a greater diversity of clinical syndromes as AKI (40\%), chronic renal disease (40\%), urinary abnormalities (10\%) and nephrotic syndrome (10\%) (table 4).

\section{Discussion}

In recent years, the number of older people has grown. According to the Spanish National Statistics Institute (INE), the population aged over 64 in Spain will double over the next 40 years to represent $30 \%$ of the total [16]. In the middle of this century, life expectancy for men
Table 3. Correlation between clinical and histological findings

\begin{tabular}{|c|c|c|c|}
\hline $\begin{array}{l}\text { Clinical } \\
\text { presentation }\end{array}$ & Histological diagnosis & Cases & $\%$ \\
\hline \multirow{12}{*}{$\begin{array}{l}\text { Nephrotic } \\
\text { syndrome }\end{array}$} & Amyloidosis & 5 & 22.7 \\
\hline & Membranous nephropathy & 5 & 22.7 \\
\hline & Minimal change nephropathy & 2 & 9.1 \\
\hline & FSGS & 2 & 9.1 \\
\hline & IgA nephropathy & 2 & 9.1 \\
\hline & Membranoproliferative GN & 1 & 4.5 \\
\hline & Fibrillary GN & 1 & 4.5 \\
\hline & Light-chain nephropathy & 1 & 4.5 \\
\hline & Diabetic glomerulopathy & 1 & 4.5 \\
\hline & Sclerosis ${ }^{1}$ & 1 & 4.5 \\
\hline & Other ${ }^{2}$ & 1 & 4.5 \\
\hline & Total & 22 & \\
\hline \multirow{4}{*}{$\begin{array}{l}\text { Nephritic } \\
\text { syndrome }\end{array}$} & Endocapillary GN & 1 & 33.3 \\
\hline & Crescentic GN type 3 (vasculitis) & 1 & 33.3 \\
\hline & Other ${ }^{2}$ & 1 & 33.3 \\
\hline & Total & 3 & \\
\hline \multirow{3}{*}{$\begin{array}{l}\text { Asymptomatic } \\
\text { urinary } \\
\text { abnormalities }\end{array}$} & Crescentic GN type 3 (vasculitis) & 1 & 50 \\
\hline & Light-chain nephropathy & 1 & 50 \\
\hline & Total & 2 & \\
\hline \multirow[t]{15}{*}{ AKI } & Amyloidosis & 6 & 18.8 \\
\hline & Crescentic GN types 1 and 2 & 5 & 15.6 \\
\hline & Crescentic GN type 3 (vasculitis) & 4 & 12.5 \\
\hline & IgA nephropathy & 3 & 9.4 \\
\hline & Endocapillary GN & 2 & 6.3 \\
\hline & Acute interstitial nephritis & 2 & 6.3 \\
\hline & Membranous nephropathy & 1 & 3.1 \\
\hline & Goodpasture syndrome & 1 & 3.1 \\
\hline & Diabetic glomerulopathy & 1 & 3.1 \\
\hline & Acute tubular necrosis & 1 & 3.1 \\
\hline & Myeloma kidney $^{3}$ & 1 & 3.1 \\
\hline & Chronic interstitial nephritis & 1 & 3.1 \\
\hline & Unclassifiable & 3 & 9.4 \\
\hline & Other $^{2}$ & 1 & 3.1 \\
\hline & Total & 32 & \\
\hline Chronic & Crescentic GN type 3 (vasculitis) & 4 & 44.4 \\
\hline \multirow[t]{5}{*}{ kidney disease } & Chronic interstitial nephritis & 2 & 22.2 \\
\hline & IgA nephropathy & 1 & 11.1 \\
\hline & Amyloidosis & 1 & 11.1 \\
\hline & Sclerosis ${ }^{1}$ & 1 & 11.1 \\
\hline & Total & 9 & \\
\hline
\end{tabular}

\footnotetext{
${ }^{1}$ Presence of scarring without the typical presentation of the primary FSGS.

${ }^{2}$ Other refers to mixed histopathological findings.

${ }^{3}$ Myeloma kidney or light-chain cast nephropathy.
} 
Table 4. Clinical syndromes associated with more frequent histological patterns

\begin{tabular}{llllll}
\hline Histological diagnosis & NS, n (\%) & ANS, n (\%) & AUA, n (\%) & AKI, n (\%) & CKD, n (\%) \\
\hline Amyloidosis & $5(41)$ & 0 & 0 & $6(50)$ & $1(9)$ \\
Crescentic GN type 3 (vasculitis) & 0 & $1(10)$ & $1(10)$ & $4(40)$ & $4(40)$ \\
Membranous nephropathy & $5(83)$ & 0 & 0 & $1(17)$ & 0 \\
Crescentic GN types 1 and 2 & 0 & 0 & 0 & $5(100)$ & 0 \\
IgA nephropathy & $2(33)$ & 0 & 0 & $3(50)$ & $1(17)$ \\
\hline
\end{tabular}

NS = Nephrotic syndrome; ANS = acute nephritic syndrome; AUA = asymptomatic urinary abnormalities; $\mathrm{AKI}=$ acute kidney injury; CKD = chronic kidney disease.

will exceed 84 years and that of women 90 years. Consequently, the concept of 'elderly' has changed, making it difficult to compare studies over the past three decades. Several papers published in the 1980s and 1990s consider elderly people to be over 65 years old or even 60 years old, ages that do not reflect the current situation $[4,5,9,10]$. Different terms, such as 'very old', 'older', 'very elderly' or even 'old-old patients' have been used to define the aging population. Few studies analyze octogenarian patients, an age range universally considered as old.

In the field of nephropathology, only two studies have analyzed the clinical and histological characteristics of octogenarians $[11,12]$, both were conducted in the USA. No series are available from other countries and none focus on patients aged over 85 years, an increasingly prevalent group.

Consistent with the results of other authors, we found that the number of renal biopsies performed in this age group increased $[11,13,17]$. Age has traditionally been considered a classic risk factor for complications in renal biopsies, and some authors have observed a higher rate of bleeding [15], which has been associated with smaller kidney size, alterations in hemostasis, and thinning of the renal cortex [18]. For some time now, the difficulty in interpreting biopsy findings has been attributed to the aging process. Increased glomerulosclerosis and vascular or non-specific interstitial abnormalities can make it difficult to differentiate between conditions arising from normal aging process and those with pathological significance [19]. Consequently, a certain degree of controversy surrounds the risk-benefit ratio of renal biopsy in the elderly [20-23]. However, not all authors have found higher rates of biopsy-related complications in the elderly population than in younger populations $[11,22,24,25]$.
Especially relevant is the work performed in octogenarians by Nair et al. [11], who observed a low rate of complications, similar to that of younger patients. Histological diagnosis made it possible to change treatment in $40 \%$ of cases, a figure that reached $67 \%$ in the study by Moutzouris et al. [12]. Nair et al. [11] found a remarkable percentage of immunoallergic nephritis as a cause of AKI. Frequently associated with pharmacological therapy, this condition is not uncommon among elderly patients receiving several treatments. Early diagnosis based on histological data can make it possible to halt or reverse the development of renal injury [26,27], and early treatment with corticosteroids has recently been shown to improve prognosis [28]. In patients with AKI, biopsy can facilitate the differential diagnosis with acute tubular necrosis and enable initiation of early corticosteroid treatment [28]. These findings highlight the need to develop protocols and guidelines on the indication of this procedure, such as those published by Cagnoli [29]. In our series, immunoallergic nephritis accounted for $6 \%$ of cases of AKI, far below the $21 \%$ described by Nair et al. [11] and $18 \%$ reported by Haas et al. [6], although similar to the $7.2 \%$ of cases reported by Moutzouris et al. [12] in a population of octogenarians.

As is the case with immunoallergic nephritis, GN can also benefit from specific treatment once a histologybased diagnosis is made $[30,31]$. A recent study in patients aged over 60 years (defined as elderly by the authors) with nephrotic syndrome showed greater survival as a result of biopsy-based diagnosis [32]. Renal biopsy enables a rapid and accurate diagnosis to made, with few complications, and, consequently, specific treatment to be applied. Therefore, its use in the elderly population seems more than justified $[22,33]$. In a critical review of the literature on histological diagnosis of primary glomerular pathology, McGrogan et al. [34] 
emphasized the need to increase the number of renal biopsies in the elderly population, which is increasing in size.

One of the striking aspects of our study was the clear predominance of males (male-to-female ratio of 1.5). This finding contrasts with those of the only studies in octogenarians, in which women predominated, probably due to greater life expectancy $[11,12]$. In previously published data from the Spanish Registry of Glomerulonephritis, the gender ratio was similar in all age groups: 1.3 in patients aged less than 15 years, 1.7 in patients aged between 15 and 65, and 1.3 in those aged over $65[3]$.

Analysis of the different indications for renal biopsy revealed that AKI accounted for $47 \%$ of the cases studied in our series. We previously reported that AKI was the third leading cause of renal biopsy in all age groups $[1-3]$. However, as age increases, we observe an increase in the percentage of biopsies indicated due to acute deterioration of renal function, which was already the leading cause in patients over 65 years. This syndrome was also considered the first indication described by Haas et al. [6] and Moutzouris et al. [12], although the latter included acute nephritic syndrome in the group of AKI, once again highlighting the heterogeneity of published studies [34].

Recently, the incidence of elderly patients initiating chronic dialysis after non-recovery from AKI has increased [35]. However, the indication of renal biopsy to aid diagnosis and establish treatment has not been discussed [36].

In our series, the most frequent histological diagnosis in patients presenting with AKI was amyloidosis (primary and secondary). Moreover, it was the most common cause of nephrotic syndrome, together with membranous nephropathy. Amyloidosis is very common in the elderly population, constituting the first or second leading cause of nephrotic syndrome $[8-10,12,37,38]$. One of the peculiarities of these diseases in the elderly is the high frequency of secondary diseases, such as amyloidosis-related disorders or paraneoplastic membranous nephropathy.

The frequency of amyloidosis as a cause of AKI is much higher in this age group than other traditionally prevalent conditions, such as pauci-immune GN associated with vasculitis. In our study, all patients diagnosed with amyloidosis had decreased creatinine clearance at the time of biopsy and proteinuria in the nephrotic range, which is highly suggestive of the known poor prognosis of this entity [39].

Renal Biopsy in the Elderly
In most studies on elderly patients, pauci-immune GN associated with vasculitis is the main cause of acute deterioration of renal function $[6,7,11,12]$. The role of ANCA testing should be taken into account when interpreting data on the early diagnosis of systemic vasculitis. Using this test enables us to establish a diagnosis and start treatment early ( $<6 \mathrm{~h})$, thus reducing the need to perform a biopsy. Consequently, data on the histological diagnosis of crescentic GN type 3 associated with vasculitis underestimate the true incidence of this disease. It is therefore particularly important to bear in mind this entity, as many patients begin immunosuppressive therapy without evidence from a biopsy.

IgA nephropathy was also associated with a striking incidence of AKI at the time of the biopsy. Wen and Chen [40] recently described the presence of severe renal manifestations in elderly patients diagnosed with this entity. As was the case with our patients, these authors reported a higher incidence of AKI and nephrotic syndrome. Interestingly, the indication for renal biopsy was acute or chronic renal function impairment in two-thirds of patients and nephrotic syndrome in the remaining third, although the authors did not state whether this procedure was indicated with the isolated finding of hematuria. There is no doubt that this is due to the criterion of nephrologists not to take biopsy specimens. All our patients with IgA nephropathy showed decreased GFR and proteinuria $>1$ g/day, revealing the same frequency of nephrotic syndrome as FSGS or minimal change nephropathy. Although the number of patients with nephrotic syndrome in our series is small, our data illustrate the severity of this condition in this population and provide further evidence of the different presentations and behavior of the main kidney diseases in the elderly, in whom symptoms can differ from the classic pattern of $\operatorname{Ig}$ A nephropathy in younger patients. Consequently, renal biopsy should be assessed as a diagnostic technique of choice in this population.

Our study has a series of limitations. First, biopsy complications were not recorded. Second, no data were collected for more complex analytical parameters, such as autoimmunity and the presence of ANCAs. Third, the clinical questionnaire accompanying each renal biopsy did not include treatment or patient outcome. Classification of glomerular lesions has not been changed since 1994 in order to not alter the pathologist criteria, so some terms could be not updated. Finally, the histopathological diagnosis of diabetic glomerulophaty or amyloidosis due to the indication of biopsy because of AKI probably responds to the lack of creatinine monitoring previously to

Am J Nephrol 2012;35:230-237 
the determination, or to the absence of recuperation after a renal function deterioration. In this regard, prospective studies are necessary to provide a clearer picture of the risk-benefit ratio of renal biopsy and potential treatments in this age group.

In conclusion, renal biopsy in patients aged over 85 years provides us with important diagnostic information that can guide treatment. AKI is the main indication for biopsy, with amyloidosis and crescentic GN as the most frequently diagnosed diseases, although the latter finding is probably underestimated as a result of ANCA testing. Finally we must remember that the manifestations of renal disease in the elderly occasionally differ from the patterns observed in other age groups. Therefore, renal biopsy should be performed on an in- dividual basis in order to improve prognosis by providing an accurate diagnosis and enabling specific treatment to be initiated.

\section{Acknowledgments}

We thank all the participating hospitals that sent us the results of their renal biopsies. We also thank Thomas O'Boyle for proofreading the manuscript.

\section{Disclosure Statement}

The authors have no conflicts of interest to disclose.

\section{References}

-1 Rivera F, López-Gómez JM, Pérez García R: Clinicopathological correlations of renal pathology in Spain. Kidney Int 2004;66:898904

2 Rivera F, López-Gómez JM, Pérez García R: Frequency of renal pathology in Spain 19941999. Nephrol Dial Transplant 2002;17: 1594-1602.

-3 López-Gómez JM, Rivera F, on behalf of Spanish Registry of Glomerulonephritis: Renal biopsy findings in acute renal failure in the cohort of patients in the Spanish Registry of Glomerulonephritis. Clin J Am Soc Nephrol 2008;3:674-681

4 Moorthy AV, Zimmerman SW: Renal disease in the elderly: clinicopathologic analysis of renal disease in 115 elderly patients. Clin Nephrol 1980;14:223-229.

-5 Kingswood JC, Banks RA, Tribe CR, OwenJones J, Mackenzie JC: Renal biopsy in the elderly: clinicopathological correlations in 143 patients. Clin Nephrol 1984;22:183-187.

6 6 Haas M, Spargo BH, Wit EJ, Meehan SM: Etiologies and outcome of acute renal insufficiency in older adults: a renal biopsy study of 259 cases. Am J Kidney Dis 2000;35:433447.

7 Ferro G, Dattolo P, Nigrelli S, Michelassi S, Pizzarelli F: Clinical pathological correlates of renal biopsy in elderly patients. Clin Nephrol 2006;65:243-247.

$\checkmark 8$ Preston RA, Stemmer CL, Matterson BJ, Perez-Stable E, Pardo V: Renal biopsy in patients 65 years of age or older. An analysis of the results of 334 biopsies. J Am Geriatr Soc 1990;38:669-674.

-9 Komatsuda A, Nakamoto Y, Imai H, Yasuda T, Yanagisawa MM, Wakui H, Ishino T, Satoh K, Miura AB: Kidney diseases among the elderly. A clinicopathological analysis of 247 elderly patients. Inter Med 1993;32:377-381.
10 Davison AM, Johnston PA: Glomerulonephritis in the elderly. Nephrol Dial Transplant 1996;11:34-37.

-11 Nair R, Bell JM, Walker PD: Renal biopsy in patients aged 80 years and older. Am J Kidney Dis 2004;44:618-626.

-12 Moutzouris DA, Herlitz L, Appel GB, Markowitz GS, Freudenthal B, Radhakrishnan J, D'Agati VD: Renal biopsy in the very elderly. Clin J Am Soc Nephrol 2009;4:1073-1082.

13 Oreopoulos DG, Glassock RJ, Jassal SV, O'Hare AM, Rosner MH, Swidler MA, Williams ME, Wiggins J: Geriatric nephrology: another milestone in a 25 -year journey Nephrol Self-Assess Prog 2011;10:6-57.

14 Solez K, Racusen LC: Role of the renal biopsy in acute renal failure; in Ronco C, Bellomo R, La Greca G (eds): Blood Purification in Intensive Care. Contrib Nephrol. Basel, Karger, 2001, vol 132, pp 68-75

15 Whittier WL, Korbet SM: Timing of complications in percutaneous renal biopsy. J Am Soc Nephrol 2004;15:142-147.

16 Spanish National Statistics Institute, 2010 www.ine.es/prensa/np587.pdf (in Spanish).

17 Stratta P, Segoloni GP, Canavese C, Sandri L, Mazzucco G, Roccatello D, Manganaro M, Vercellone A: Incidence of biopsy-proven primary glomerulonephritis in an Italian province. Am J Kidney Dis 1996;27:631-639.

18 Korbet SM: Percutaneous renal biopsy. Semin Nephrol 2002;22:254-267.

19 Zhou XJ, Rakheja D, Yu X, Saxena R, Vaziri ND, Silva FG: The aging kidney. Kidney Int 2008;74:710-720.

20 Moran D, Korzets Z, Bernheim J, Bernheim J, Yaretzky A: Is renal biopsy justified for the diagnosis and management of the nephrotic syndrome in the elderly? Gerontology 1993 39:49-54.
21 Levison SP: Renal disease in the elderly: the role of the renal biopsy. Am J Kidney Dis 1990;16:300-306

22 Jefferson JA, Alpers CE: Diagnosis: should renal biopsies be performed in the very elderly? Nat Rev Nephrol 2009;5:561-562.

23 Parrish AE: Complications of percutaneous renal biopsy: a review of 37 years' experience. Clin Nephrol 1992;38:135-141.

24 Uezono S, Hara S, Sato Y, Komatsu H, Ikeda N, Shimao Y, Hayashi T, Asada Y, Fujimoto S, Eto T: Renal biopsy in elderly patients: a clinicopathological analysis. Ren Fail 2006; 28:549-555.

-25 Rychlík I, Jancová E, Tesar V, Kolsky A, Lácha J, Stejskal J, Stejskalová A, Dusek J, Herout V: The Czech registry of renal biopsies. Occurrence of renal diseases in the years 1994-2000. Nephrol Dial Transplant 2004; 19:3040-3049.

- 26 Anderson S, Eldadah B, Halter JB, Hazzard WR, Himmelfarb J, Horne FM, Kimmel PL, Molitoris BA, Murthy M, O'Hare AM, Schmader KE, High KP: Acute kidney injury in older adults. J Am Soc Nephrol 2011;22: 28-38.

27 Michel DM, Kelly CJ: Acute interstitial nephritis. J Am Soc Nephrol 1998;9:506-515.

28 González E, Gutiérrez E, Galeano C, Chevia C, de Sequera P, Bernis C, Parra EG, Delgado R, Sanz M, Ortiz M, Goicoechea M, Quereda C, Olea T, Bouarich H, Hernández Y, Segovia B, Praga M, Grupo Madrileño de Nefritis Intersticiales: Early steroid treatment improves the recovery of renal function in patients with drug-induced acute interstitial nephritis. Kidney Int 2008;73:940-946.

29 Cagnoli L, Italian Society of Nephrology: Instructions and implementations for percutaneous renal biopsy. Guidelines for the therapy of glomerular nephropathies. G Ital $\mathrm{Ne}$ frol 2003;20:S3-S47. 
30 Glassock RJ: Glomerular disease in the elderly population. Geriatr Nephrol Urol 1998;8: 149-154.

31 Donadio JV Jr: Treatment and clinical outcome of glomerulonephritis in the elderly. Contrib Nephrol 1993;105:49-57.

- 32 Yoon HE, Shin MJ, Kim YS, Choi BS, Kim BS, Choi YJ, Kim YO, Yoon SA, Yang CW: Clinical impact of renal biopsy on outcomes in elderly patients with nephrotic syndrome. Nephron Clin Pract 2010;117:c20-c27.
33 Bergesio F, Bertoni E, Bandini S, Rosati A, Salvadori M: Changing pattern of glomerulonephritis in the elderly: a change of prevalence or a different approach? Contrib Nephrol 1993;105:75-80.

34 McGrogan A, Franssen CF, de Vries CS: The incidence of primary glomerulonephritis worldwide: a systematic review of the literature. Nephrol Dial Transplant 2011;26:414430.

-35 Schmitt R, Coca S, Kanbay M, Tinetti ME, Cantley LG, Parikh CR: Recovery of kidney function after acute kidney injury in the elderly: a systematic review and meta-analysis. Am J Kidney Dis 2008;52:262-271.

36 Schlanger LE, Bailey JL, Sands JM: Geriatric nephrology: a missing area of nephrology's expertise. Nephrol Self-Assess Prog 2011;10 $1-5$.
7 Modesto-Segonds A, Ah-Soune MF, Durand D, Suc JM: Renal biopsy in the elderly; in Sessa A, Meroni M, Battini G (eds): Glomerulonephritis in the Elderly. Contrib Nephrol. Basel, Karger, 1993, vol 105, pp 107-116.

38 Cameron JS: Nephrotic syndrome in the elderly. Semin Nephrol 1996;16:319-329.

39 Lachmann HJ, Gillmore JD: Renal amyloidosis. Br J Hosp Med 2010;71:83-86.

-40 Wen YK, Chen ML: Differences in new-onset IgA nephropathy between young adults and the elderly. Ren Fail 2010;32:343-348. 